\title{
Zemin Taşıma Gücünün Rijit ve Esnek Üstyapıların Kalınlıklarına ve Maliyetlerine Etkisi
}

\author{
Tacettin GEÇKIL ${ }^{1}$, Mehmet Mahmut TANYILDIZI ${ }^{2 *}$ \\ 1 İnönü Üniversitesi, Mühendislik Fakültesi, İnşaat Mühendisliği Bölümü, Malatya, Türkiye \\ 2 'nci Ordu Komutanlığı, Malatya, Türkiye \\ 1 tacettin.geckil@inonu.edu.tr, ${ }^{* 2}$ mmtanyildizi@hotmail.com
}

\begin{abstract}
Öz: Yol otoriteleri, minimum bakım gerektiren, trafik güvenliği yüksek, uzun ömürlü ve ekonomik yolları hedeflemektedirler. Taşıma gücü zayıf zeminlerde ekonomik bir üstyapı inşası güç olmaktadır. Bu nedenle, esnek ve rijit üstyapıların projelendirilmesinde kullanılan zemin parametrelerinin seçiminde, ortam ve koşullara göre en uygun seçeneğin tercih edilmesi ekonomik açıdan önem arz etmektedir. Bu çalışmada, esnek ve rijit yol üstyapısının projelendirilmesinde kullanılan AASHTO (1986) (American Association of State Highway and Transportation Officials) metodundaki 'Taban Zemini Esneklik Modülü $M_{R}$ (psi)' ile 'Yatak Katsayısı k (pci)' parametreleri, esnek ve rijit üstyapılarda hem maliyet hem de tabaka kalınlıkları açısından araştırılmıştır. Bu amaçla, esnek üstyapılarda esnek üstyapı sayısını en çok etkileyen parametre taban zemini esneklik modülü $\left(\mathrm{M}_{\mathrm{R}}\right)$ iken rijit üstyapılarda yatak katsayısı (k) üstyapı beton kaplama kalınlığını en az etkileyen parametre olarak tespit edilmiştir. Esnek üstyapılarda taban zemini esneklik modülü $M_{R}$ 'nin gerçek değerinden \%50 küçük değerin alınmış olması durumunda çift şeritli bölünmüş (platform genişliği $20 \mathrm{~m}$ ) $100 \mathrm{~km}$ uzunluğundaki esnek bir üstyapıda maliyetin yaklaşı 2.568.000 TL artış gösterdiği, rijit üstyapıda ise yatak katsayısı (k)'nın gerçek değerinden \%50 küçük değerin alınmış olması durumunda çift şeritli bölünmüş (platform genişliği $20 \mathrm{~m}$ ) $100 \mathrm{~km}$ uzunluğundaki rijit bir üstyapıda maliyetin yaklaşık 114.000 TL artış gösterdiği tespit edilmiştir. Sonuçta, karayolu üstyapılarının tasarımı; tasarım ömrü boyunca tahmin edilen trafik yükleri ve çevre koşulları için üstyapı tabaka kalınlıklarının hesabı ve malzeme özelliklerinin belirlenmesi esasına dayandığından, ' $M_{R}$ ' değerinin gerçek değerinden küçük alınması durumunda yatırım giderlerinin gereksiz yere artırılmış ve bu durumun ekonomik zararlara yol açabileceği, ' $\mathrm{k}$ ' değerinin ise üstyapı maliyetine önemli bir etkisinin olmadığ 1 tespit edilmiştir.
\end{abstract}

Anahtar kelimeler: Rijit üstyapı, esnek üstyap1, AASHTO metodu, taban zemini esneklik modülü, yatak katsayısı.

\section{Effect of Bearing Capacity of Soil on the Thickness and Cost of Rigid and Flexible Superstructures}

Abstract: Road authorities aim at long-lasting and economic roads that require minimal maintenance with high traffic safety. It is difficult to build an economic superstructure on poor bearing soil. Thus, it is economically important to choose the most suitable option for the environment and conditions in the selection of the floor parameters used for the design of flexible and rigid top structures. In this study, 'Floor Base Flexibility Module $M_{R}$ (psi)' and 'coefficient of soil reaction k (pci)' parameters in AASHTO (1986) (American Association of State Highway and Transportation Officials) method that have been used in the design of flexible and rigid road superstructure were investigated in flexible and rigid superstructures in terms of both cost and layer thicknesses. For this purpose, it has been determined that while the parameter that affects the flexible superstructure number in superstructures most is floor flexibility module $\left(\mathrm{M}_{\mathrm{R}}\right)$, the bed coefficient $(\mathrm{k})$ in the rigid superstructures is the parameter that affects the thickness of the superstructure concrete cladding least. It is evaluated that the cost of a flexible pavilion with a double-stranded split (platform width $20 \mathrm{~m}$ ) with a length of 100 kilometres increases by approximately 2.568.000 TL in the event that the base floor flexibility module has a value of $\% 50$ smaller than the actual value of $\mathrm{M}_{\mathrm{R}}$ in flexible superstructures, however it has also been determined in rigid superstructures that if a value which is $\% 50$ smaller than the actual value of the bed coefficient $(\mathrm{k})$ is taken, the cost of a rigid superstructure with a double-strand split (platform width $20 \mathrm{~m}$ ) is reduced by approximately $114.000 \mathrm{TL}$. As a result, it has been determined that since the design of the highway pavements is based on the determination of the superstructure layer thicknesses and material properties for the estimated traffic loads and environmental conditions throughout the design life, the investment costs are increased unnecessarily and this can cause economic losses if the ' $M_{R}$ ' value is greater than the actual value, and ' $k$ ' value has no significant effect on the cost of superstructure.

Key words: Rigid pavement, flexible pavement, AASHTO Method, base floor elasticity module, bearing coefficient.

\section{Giriș}

Yollar, bölgenin sosyo-ekonomik durumuna bağlı olarak ihtiyaç ve talepleri karşılayacak şekilde tasarlanmaktadır. Yol kullanıcısı olarak sürücüler, düzgün, konforlu, kayma direnci yüksek, hızlı erişimli, ulaşım

\footnotetext{
* Sorumlu yazar: mmtanyildizi@ hotmail.com. Yazarların ORCID Numaras1: ${ }^{10000-0001-8070-6836, ~}{ }^{20000-0001-5992-2665}$
} 
maliyeti ve gürültü seviyesi düşük yollar talep ederken, yol otoriteleri, dayanıklı minimum bakım gerektiren, kalıcı deformasyonlara karşı dirençli, trafik güvenliği yüksek, uzun ömürlü yolları hedeflemektedirler [1].

Bir yol üstyapısı değişik elemanlardan oluşur. $\mathrm{Bu}$ elemanlar, üstyapının proje ömrü boyunca emniyetli bir şekilde ve her türlü iklim koşulları altında hizmet verebilmesini ayrıca çok sayıda aracın üzerinden geçmesini sağlayacak koşulları yerine getirebilmelidir [2]. Üstyapı tasarımında ampirik, ampirik analitik ve analitik olmak üzere üç yöntem kullanılmaktadır. Ampirik yöntemler uygulamalardan kaynaklanan bilgi birikimleri ve özel olarak yapılmış deneme yollarından edinilen deneyimlere dayanmaktadır. Dolayısıyla ampirik yöntemler, üzerinde uygulandığı deneme yolunun koşullarından daha farklı koşullarda uygun sonuç vermemektedir. Buna karşı1lk analitik yöntem; teorik analiz ve bitümlü malzemelerin mekanik özelliklerini kullanmakta ve her türlü koşulda uygulanabilmektedir [3]. Bu mekanik özellikler kapsamında stabilizasyonla zeminin; mukavemet, rijitlik, basınç dayanımı, geçirgenlik, drenaj ve donma hassasiyeti gibi özellikleri iyileştirilebilir. Yol altyapısını stabil bir duruma getirmek için birçok stabilizasyon metotları mevcuttur. Ülkemizde genellikle mekanik stabilizasyon metodu uygulanmaktadır. Kireç ve çimentonun çok miktarda bulunması nedeniyle zemin-kireç ve zemin-çimento stabilizasyonu da karayollarımızda kullanılmaktadır. Zeminasfalt stabilizasyonu ile zeminin su tutması azaltılarak geçirimsizliği sağlanır, zemin daneleri birbirine bağlanarak zeminin kohezyonu ve stabilitesi artırılıp üstyapı kalınlığı azaltılabilir [4]. Ayrıca, kaplama tabakasında kullanılan bitümlü sıcak karışımların mühendislik özelliklerini iyileştirmek için iki temel yoldan birisi gradasyonu ve dolayısıyla asfalt çimentosu oranlarını değiştirmektir. Diğer bir yol ise ya bitüme ya da doğrudan karışıma ilave edilen katkı maddeleriyle bitümlü sıcak karışım özelliklerini iyileştirmektir. Temel ve alttemel tabakalarında ise kalitesi yüksek malzeme kullanımı ve uygun gradasyon seçimi ile iyileştirmeler yapılmaktadır. Bu üç tabaka yüksek kalitede imal edilmiş olsalar da üzerine oturdukları zemin yeterli taşıma gücüne sahip değil ise yollarda altyapı kusurundan kaynaklanan tekerlek izi, oturmalar ve çatlamalar gibi bozulmalar meydana gelmektedir. $\mathrm{Bu}$ gibi kusurları önlemek ya zemin taşıma gücünü artırmakla ya da yüksek maliyetlere neden olan tabaka kalınlıklarının artııılmasıyla mümkündür [5]. Prabakar, Dendorkar ve Morchhale (2004) üç farklı zemine \%9-46 oranlarında uçucu kül ilave ederek bu zeminlerin Kaliforniya Taşıma Oranı (CBR) değerleri, kesme gerilmesi parametreleri ve şişme potansiyellerini incelemiştir. Sonuçta uçucu kül ilavesinin, likit limit ve plastisite indisi en düşük olan CL sınıfındaki zeminde en fazla iyileştirme yaptı̆̆ı belirtilmiştir [6]. Senol, Edil, Bin-Shafque, Acosta ve Benson (2006) ince gradasyonlu killi zeminlerde (CL-CH) yüksek kalsiyum içerikli uçucu kül ve çimento ile stabilizasyonun etkinliğini incelemişlerdir. Değişik oranlardaki uçucu kül ve çimento karışımlı numunelerin elastisite modülleri ve 90 günlük basınç dayanımları ve CBR değerleri tespit edilmişsir. Uçucu kül ve çimento ile iyileştirilmiş killi zemin üzerindeki esnek üst yapının analizi yapılarak geleneksel üstyapılar ile karşılaştııılmış ve stabilizasyonun teknik faydaları açıkça ortaya konulmuștur. Dört ayrı tesisten elde edilen, ikisi yüksek oranda $\mathrm{CaO}$, ikisi de yüksek oranda karbon içeren uçucu küllerin yumuşak zeminlerin stabilizasyonundaki etkilerinin incelendiği çalışmada, kül içeriğinin artması ile değişik zemin cinslerine göre CBR değerinin 2 ile 18 kat arasında, basınç mukavemetinin ise 2 ile 7 kat arasında arttığı, en fazla artıșın \%20 uçucu kül içerikli CL sınıfındaki zeminde olduğu belirtilmiştir [7]. Lav ve Goktepe (2006) gerçekleştirdikleri çalışma ile çimento stabilizasyonlu uçucu kül malzemesinin temel malzemesi olarak kullanılabilmesi için çimento miktarının en az \%8, tabaka kalınlığının ise $30 \mathrm{~cm}$ olması gerektiğini tespit etmişlerdir [8]. Chauhan, Mittal ve Mohanty (2008) optimum uçucu kül oranı tek eksenli basınç deneyi sonuçları dikkate alınarak yaptıkları araștırmada en iyi sonuca $\% 70$ kum ve $\% 30$ uçucu kül karıșımının sahip olduğunu, bu karıșıma \%1 polipropilen lif ilavesinin tek eksenli basınç değerini önemli ölçüde artırdığını belirtmişlerdir [9]. Cai, Shi ve Tang (2006) lif katkısı ve kireç içeren başka bir çalışmada en yüksek basınç dayanımlarının ve içsel sürtünme açılarının $\% 0,25$ lif ve $\% 5$ kireç kullanılması durumunda elde edildiğini ve kireç oranının artması ile șişme potansiyelinin azaldığını belirtmişlerdir [10]. Gerald, Miller ve Azadb (2000) portlant çimentosu üretiminde açığa çıkan atık malzemenin (çimento firın tozu, CKD) düşük ve yüksek plastik zeminlerde stabilize malzemesi olarak kullanılabilirliğini araştırmışlardır. Sonuçta CKD ilavesi ile tek eksenli basınç dayanımının iyileştiği, bu iyileşmenin düşük PI değerlerine sahip zeminlerde daha fazla olduğu, CKD katkılı zeminlerin basınç dayanımlarının 7-14 gün içerisinde hızlı bir şekilde arttığı daha sonra artı̧ hızının azaldığı, CKD ilavesi ile optimum su oranının arttığı ve maksimum kuru birim hacim ağırlığının azaldığı belirtilmiştir [11]. Dermataş ve Meng (2003) içerisinde $\mathrm{Ca}, \mathrm{Mg}$, Si ve Al oksit içeren atık malzemelerle zemin stabilizasyonu yaparak zeminlerin şişme potansiyellerini ve tek eksenli basınç dayanımlarını incelemişlerdir. Sonuçta şişme potansiyelini azaltmada önemli bir etkiye sahip olabilmesi için kirecin \%4 oranından fazla kullanılması gerektiği, aynı orandaki MgO'in en iyi performansı gösterdiği belirtilmiştir. Uçucu kül içerisinde bulunan $\mathrm{CaO}$ 'in puzzolanik bir etki yaptığ $\% 25$ uçucu kül ile \%10 kireç katkılı zeminlerin basınç dayanımlarının çok yüksek olduğu belirtilmiştir [12]. Eren ve Filiz (2009) yaptıkları çalışmada değişik oranlarda çimento ve kireç katkılı zeminin CBR değerlerini incelemiștir. Kireç oranının \%8 değerine kadar CBR değerinin arttığı daha sonra düşeşe geçtiği kireç katkılı zeminin hiç şişme göstermediği tespit edilmiştir [13]. 
Wu, Zhang ve Tao (2010) kalsiyum sülfat katkılı ve yüksek firın cürufu içeren, kalsiyum sülfat katkılı ve uçucu kül içeren ve kırma taştan yapılmış temel tabakalarından oluşan üç farklı kesit hazırlamışlardır. Tekerlek izi deneyinden, 12,5 mm tekerlek izinde kalsiyum sülfat katkılı yüksek firın cüruflu ve kalsiyum sülfatlı uçucu küllü kesitlerde yorulma çatlağı ve timsah sırtı çatlakların oluşmadığ 1 buna karşın temel tabakası kırma taştan oluşan kesitte ciddi derecede çatlakların oluştuğu tespit edilmiştir. Yapılan çalışmalarda zemin stabilizasyonunda kireç, çimento, uçucu kül gibi malzemeler ayrı ayrı yada birlikte kullanılarak zeminlerin taşıma gücüne olan olumlu etkileri ayrıca likit limit, plastisite indisi değerlerini nasıl etkilediği belirtilmiştir [14].

Bu çalışmada; AASHTO (1986) metodundaki zemin parametrelerinin rijit ve esnek üstyapıların kalınlıklarına ve maliyetlerine etkisi araştırılmış, taban zemini esneklik modülü $M_{R}$ (psi) ile yatak katsayısı k (pci) parametrelerinin gerçek değerinden \%50 eksik alınması durumunda, beton kaplama kalınlığını ve esnek üstyapı sayısını ne ölçüde etkilediği ve sonuçta üstyapıyı oluşturan tabakaların değişik zemin taşıma gücüne göre üstyapı maliyetine etkisi tespit edilmiştir. Maliyetlerin hesaplanmasında 2018 birim fiyatları kullanılmıştır.

\section{Materyal ve Yöntem}

Bu çalışmada materyal olarak esnek ve rijit üstyapı projelendirme yöntemleri kullanılmıştır. Sırasıyla Grup İndeksi metodu (GI), CBR metodu ve AASHTO hesap yöntemleri anlatılmıştır.

\subsubsection{Grup İndeksi Yöntemi (GI)}

$\mathrm{Bu}$ metot 1945 yılında Steele tarafından ABD'de geliştirilmiş olup, taban zemininin granülometrisine ve plastisitesine bağlıdır. Grup indeksi (1) numaralı formül ile bulunur. Eğer temel ve alt temelin yeteri kadar sıkıştırıldığı kabul edilirse, üstyapının kalınlığını tayin edecek en önemli etken taban direnci olur.

$\mathrm{GI}=0.2 \times \mathrm{a}+0.005 \times(\mathrm{a} \times \mathrm{c})+0.01 \times(\mathrm{b} \times \mathrm{d})$

Burada;

a: Zeminin 200 nolu elekten geçen kısmının \%35'den büyük, fakat \%75'den küçük olan miktarıdır,

b: Zeminin 200 nolu elekten geçen kısmının \%15'den büyük, fakat \%55'den küçük olan miktarıdır,

c: Zeminin nümerik likitlik limitinin 40'dan büyük, fakat 60'dan küçük olan kısmıdır,

d: Zeminin nümerik plastiklik indisinin 10'dan büyük, fakat 30'dan küçük olan kısmıdır.

GI, 0 ile 20 arasında bir değer alır. GI=0 değeri çok iyi bir malzemeyi (yüksek taşıma kapasitesi) ve GI=20 değeri çok kötü bir malzemeyi (düşük taşıma kapasitesi) temsil eder.

\subsubsection{CBR Metodu}

1930’lu yıllarda Kaliforniya'da O.T. Porter tarafından geliştirilmiştir. İlk yıllarda havaalanı kalınlık tasarımında kullanılmış ve daha sonraları yol üstyapıları için de kullanılmaya başlamıştır. Zeminin ve granüler malzemenin CBR değeri göz önüne alınarak üstyapı kalınlığı hesaplanır [15].

CBR deneyi şu şekilde yapılır:

1. Yaklaşık $4000 \mathrm{gr}$ lık ve değişik nem değerlerinde bulunan birkaç örselenmiş zemin örneği $140 \mathrm{~kg} / \mathrm{cm}^{2}$ bir statik yük ile $15 \mathrm{~cm}$ çaplı ve $20 \mathrm{~cm}$ yükseklikteki silindirik kalın kenarlı çelik kalıplar içinde sıkıştırılır. Elde edilen numune epruvetinin yüksekliği $10 \mathrm{~cm}$ kadardır.

2. Nem-yoğunluk eğrisi çizilir ve en büyük kuru yoğunluk değerini veren numune seçilir.

3. Bu numune, içinde bulunduğu kalıpla birlikte suya bastırılır ve uygulamada elde edilecek doygunluk derecesine ulaşması amacıyla dört gün süre ile su içinde bırakılır.

Taban alanı $20 \mathrm{~cm}^{2}$ olan küçük bir silindirik piston silindirik çelik kalıp içinde bulunan numuneye batırılır. $\mathrm{Bu}$ sırada piston numuneye saplandıkça yük deformasyon bilgileri toplanır. Genellikle piston $4.5 \mathrm{~kg}$ ağırlığında bir sürşarj halkası içinden geçer. Bu halka numune yüzeyini sınırlar ve uygulamada yol temel ve zemin tabakalarının ağırlığını temsil eder. CBR değeri eşitlik (2) ile bulunur.

$\mathrm{CBR}=\frac{\text { Pistonun numune yüzeyine } 0.25 \mathrm{~cm} \text { batması için yeterli yük }}{\text { Standart kırma kaya temelde pistonun } 0.25 \mathrm{~cm} \text { batması için gerekli olan yük }}$ 
CBR değeri \% olarak ifade edilir ve CBR değeri yükseldikçe zemin sertleşir. Yatak katsayısı (k) ile taban zemini esneklik modülü $\left(\mathrm{M}_{\mathrm{R}}\right)$ arasındaki bağıntı eşitlik (3) ile verilmiştir.

$\mathrm{k}=\mathrm{M}_{\mathrm{R}} / 19.4$

Burada;

k : Yatak katsayısı (Plaka yükleme testi ile) (pci)

$\mathrm{M}_{\mathrm{R}}$ : Taban zemini esneklik modülü (Üç eksenli test ile ) (psi)

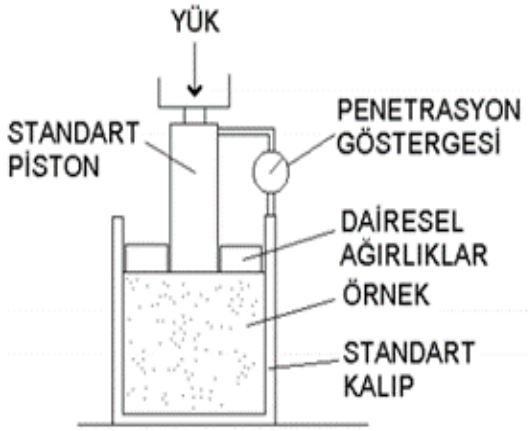

Şekil 1. CBR deney düzeneği.

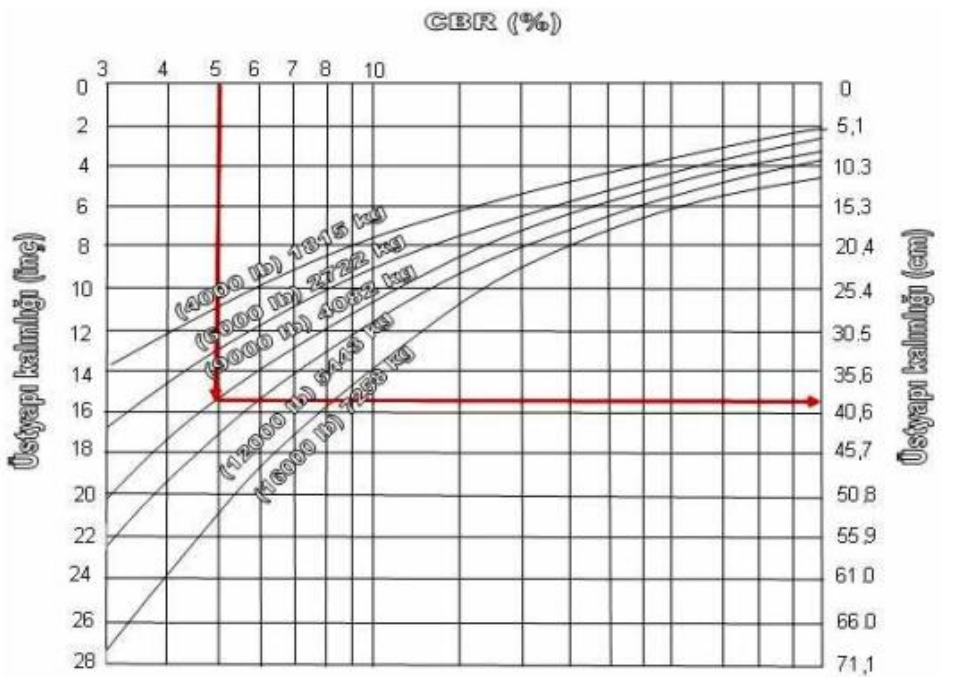

Şekil 2. CBR metodu ile üstyapı kalınlık hesap eğrisi.

\subsubsection{AASHTO metodu ile rijit üstyapı tasarımında zemin yatak katsayısının analitik incelenmesi}

AASHTO (1986) metodu, yol testi sonuçları ile standart dingil yükü tekerrür sayısının kaplamanın performansına etkisi dikkate alınarak geliştirilmiştir. Esnek kaplamaların tasarımında olduğu gibi, kaplamanın servis yeteneğindeki azalma göz önüne alınmaktadır. Beton kaplamanın performansı için AASHTO (1986) yol testinden denklem (4) deki eşitlik elde edilmiştir [16].

$\log _{10} \mathrm{~W}_{8,2}=\mathrm{Z}_{\mathrm{R}} \times \mathrm{S}_{0}+7.35 \times \log _{10}(\mathrm{D}+1)-0.06+\frac{\log _{10}[\Delta \mathrm{PSI} /(4.5-1.5)}{1+\left[1.624 \times 10^{7} /(\mathrm{D}+1)^{8.46}\right]}$

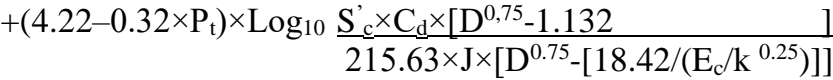

Burada;

$\mathrm{W}_{8.2}: 8,2$ ton eşdeğer tek-dingil yükü tekerrür sayıs1

$\mathrm{Z}_{\mathrm{R}} \quad$ : Standart normal sapma

$\mathrm{S}_{0} \quad$ : Trafik tahmini ve performans tahmininin bileşik standart hatası

D : Rijit üstyapı beton kaplama kalınlığı (inç)

$\triangle$ PSI: $\mathrm{P}_{0}-\mathrm{P}_{\mathrm{t}}$ (Servis kabiliyetinde azalma miktarı)

$\mathrm{P}_{0} \quad$ : Başlangıç servis kabiliyeti indeksi

$P_{t} \quad$ : Nihai servis kabiliyeti indeksi

$\mathrm{S}_{\mathrm{c}}^{\prime} \quad$ : Betonun kopma modülü (Eğilmede çekme mukavemeti) (psi)

J : Yük transfer katsayısı

$\mathrm{C}_{\mathrm{d}} \quad$ : Drenaj katsayısı

$\mathrm{E}_{\mathrm{c}} \quad$ : Betonun elastisite modülü (psi) 
$\mathrm{k} \quad$ : Zemin yatak katsayısı (pci)

$\mathrm{Bu}$ çalışmada; 8.2 ton eşdeğer tek-dingil yükü tekerrür sayısı $\mathrm{W}_{8.2}=45$ milyon, yük transfer katsayıs1 $\mathrm{J}=3.2$, drenaj katsayısı $\mathrm{C}_{\mathrm{d}}=1.0$, Betonun elastisite modülü $\mathrm{E}_{\mathrm{c}}=5$ milyon ve servis yeteneği kaybı $\Delta \mathrm{PSI}=2$ olarak alınmış, zemin yatak katsayısı k’nın, rijit üstyapı beton kaplama kalınlığı ile değişimi incelenmiştir.

Yatak katsayısı 50-1600 psi arasında, trafik tahmini ve performans tahmininin bileşik standart hatası $\% 10$ $\% 60$ arasında, güvenilirlik \%5-\%99 arasında seçilmiştir.

Yatak katsayısının (k)'nın rijit üstyapı beton kaplama kalınlığına etkisi Tablo 1'de verilmiștir. Tablodaki değerlerin değişimi Şekil 3'de grafik olarak gösterilmiştir. Şekil 3'den de görüldüğü gibi yatak katsayısının küçük değerlerinde üstyapı beton kaplama kalınlığı büyük değerler almaktadır. Yatak katsayısı arttıkça üstyapı beton kaplama kalınlığı azalmaktadır.

Yatak katsayısı (k)'nın gerçek değerinden \%50 küçük değerin alınmış olması durumunda (Kabul edilen 'k' değerinin 600 yerine herhangi bir nedenle hata yapılarak 300 alınması) üstyapı beton kaplama kalınlığında \% 3.494'lük fazla değer elde edilmiş olmaktadır.

$\mathrm{ED}=((\mathrm{D}-\mathrm{DE}) \times 100) / \mathrm{D})$

ED : Yüzdelik hata

D : Gerçek girdi parametresi kullanılarak hesaplanan üstyapı sayısı

DE : Girdi parametrelerinde tahmini bir hata kullanılarak hesaplanan üstyapı sayısı

$$
\mathrm{ED}=((\mathrm{D}-\mathrm{DE}) \times 100) / \mathrm{D})=((13.002-12.563) \times 100) / 12.563)=\% 3.494 \text { olmaktadır }
$$

Tablo 1. Yatak katsayısındaki değişime göre diğer parametrelerdeki değişim.

\begin{tabular}{|c|c|c|c|c|c|c|}
\hline$W_{8.2}$ & $\mathrm{k}$ (pi) & $S_{0}$ & $Z_{k}$ & $\mathrm{Ec}$ & $\mathrm{d}$ (inc) & $d_{(\mathrm{m})}$ \\
\hline & 50 & & & & 13,688 & 34,768 \\
\hline & 75 & & & & 13,563 & 34,450 \\
\hline & 100 & & & & 13,463 & 34,196 \\
\hline & 200 & & & & 13,182 & 33,482 \\
\hline & 400 & & & & 12,822 & 32,568 \\
\hline \multirow[t]{6}{*}{45.000 .000} & 600 & 0,35 & $-1,645$ & 5.000 .000 & 12,563 & 31,910 \\
\hline & 800 & & & & 12,350 & 31,369 \\
\hline & 1000 & & & & 12,124 & 30,795 \\
\hline & 1200 & & & & 11,895 & 30,213 \\
\hline & 1400 & & & & 11,793 & 29,954 \\
\hline & 1600 & & & & 11,586 & 29,428 \\
\hline
\end{tabular}

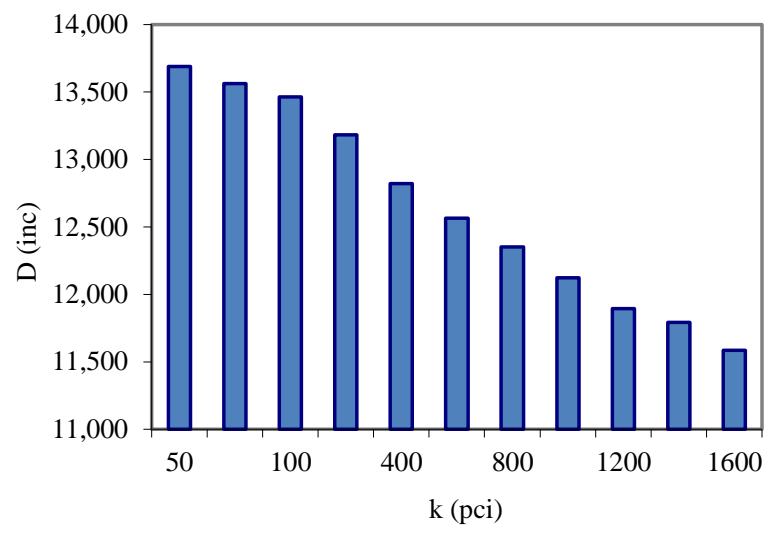

Şekil 3. Kaplama kalınlığının yatak katsayısı ile değişimi.

\subsubsection{AASHTO metodu ile esnek üstyapı tasarımında taban zemini taşıma gücünün analitik incelenmesi}

AASHTO metodu ile esnek üstyapının projelendirilmesi kısmen deneyimlere dayandırılmakla beraber, taban zemini taşıma gücü, trafik dingil yükleri ve tekerrürü ile yerel koşullar, ayrıca üstyapıda kullanılan malzemelerin birbirlerine oranla, direnç özellikleri de hesaba katılmaktadır. AASHTO yol deneyinden yararlanılarak üstyapı kalınlıklarının hesabında kullanılmak üzere üstyapıya etkiyen faktörleri içine alan AASHTO (1986) deney yolu denklemi (6) numaralı eşitlik ile verilmiştir [17].

$$
\begin{aligned}
& \log \mathrm{T}_{80}=\mathrm{Z}_{\mathrm{R}} \times \mathrm{S}_{0}+9.36 \times \log _{10}(\mathrm{SN}+1)-0.20+\frac{\log _{10}[\Delta \mathrm{PSI} /(4.2-1.5)}{0.40+\left[1094 /(\mathrm{SN}+1)^{5.19}\right]} \\
& +2.32 \log _{10} \times\left(0.145 \times \mathrm{M}_{\mathrm{R}}\right)-8.07
\end{aligned}
$$


Üst yapısı hesaplanacak yolun oturacağı taban zemininin AASHTO ile $\mathrm{M}_{\mathrm{R}}$ değeri tespit edilmektedir. Zeminin CBR değeri ile $\mathrm{M}_{R}$ değeri arasında Psi cinsinden $M_{R}=1500 \times C B R$ gibi bir ilişki mevcut olduğundan dolayı taban zemininin $\mathrm{CBR}$ değeri bilinmesi halinde $\mathrm{M}_{\mathrm{R}}$ değeri yaklaşı olarak tayin edilebilmektedir.

Burada;

$\mathrm{T}_{80}$ : Projelendirilecek yolun hizmete açılmasından, hizmet kabiliyeti indeksinin seçilen değere düşeceği değere kadar hesap şeridinin taşıyacağı tahmin edilen toplam trafiktir. (Eşdeğer standart dingil sayısı olarak)

$\mathrm{M}_{\mathrm{R}}$ : Taban zemini esneklik modülü (psi)

$\mathrm{S}_{0} \quad$ : Standart sapma

$Z_{\mathrm{R}} \quad$ : Normal standart sapma

SN : Üstyapı sayıs1

$\Delta$ PSI: Servis kabiliyeti indeksi

$\mathrm{Bu}$ çalışmada, taban zemini esneklik modülü $\mathrm{M}_{\mathrm{R}}$ 'nin, üstyapı sayısı $\mathrm{SN}$ ile değişimi incelenmiştir. Eşdeğer standart dingil yükü tekerrür sayısı $\mathrm{T}_{80}=10$ milyon, standart sapma $\mathrm{S}_{0}=0.60$, Servis kabiliyeti indeksi $\triangle \mathrm{PSI}=2.2$, taban zemini esneklik modülü 10.000 ile 250.000 arasında seçilmiştir.

Tablo 2'de $\mathrm{M}_{\mathrm{R}}$ 'nin üstyapı sayısına etkisini belirlemek için ele alınan parametrelerin değerleri, Şekil 4'de ise $M_{R}$ 'nin üstyapı sayısına etkisi verilmiştir. Şekil 4'den görüldüğü üzere, $M_{R}$ 'nin küçük değerlerinde, üstyapı sayısı büyük değerler almaktadır. Zeminin taşıma gücü arttıkça, üstyapı sayısı küçülmektedir.

$\mathrm{M}_{\mathrm{R}}$ 'nin gerçek değerinden \%50 küçük değerin alınmıș olması durumunda (Kabul edilen ' $\mathrm{M}_{\mathrm{R}}$ ' değerinin 60.000 yerine herhangi bir nedenle hata yapılarak 30.000 alınması) üstyapı sayısında \%21.34'lük fazla değer elde edilmiş olmaktadır.

$\mathrm{ED}=((\mathrm{D}-\mathrm{DE}) \times 100) / \mathrm{D})=((7,913-6.521) \times 100) / 6.521)=\% 21.34$ olmaktadır.

Tablo 2. $\mathrm{M}_{\mathrm{R}}$ İle $\mathrm{SN}$ arasındaki ilişsi.

\begin{tabular}{|c|c|c|c|c|c|c|c|}
\hline $\mathrm{T}_{80}$ & $\mathbf{M}_{\mathrm{R}}$ & $\mathbf{S}_{0}$ & $\mathrm{R}_{\mathrm{E}}$ & $\mathbf{Z}_{\mathbf{R}}$ & $\Delta \mathrm{P}$ & $\mathbf{S N}(\mathrm{inc})$ & $\mathbf{S N}(\mathrm{cm})$ \\
\hline & $10.000,00$ & & & & & 10,115 & 25,692 \\
\hline & $20.000,00$ & & & & & 8,798 & 22,347 \\
\hline & $30.000,00$ & & & & & 7,913 & 20,099 \\
\hline & $40.000,00$ & & & & & 7,336 & 18,633 \\
\hline 10.000 .000 & $60.000,00$ & 0,6 & 0,999 & $-3,090$ & 2,20 & 6,521 & 16,563 \\
\hline & $90.000,00$ & & & & & 5,672 & 14,407 \\
\hline & $130.000,00$ & & & & & 5,154 & 13,091 \\
\hline & $190.000,00$ & & & & & 4,652 & 11,816 \\
\hline & $250.000,00$ & & & & & 4,012 & 10,190 \\
\hline
\end{tabular}

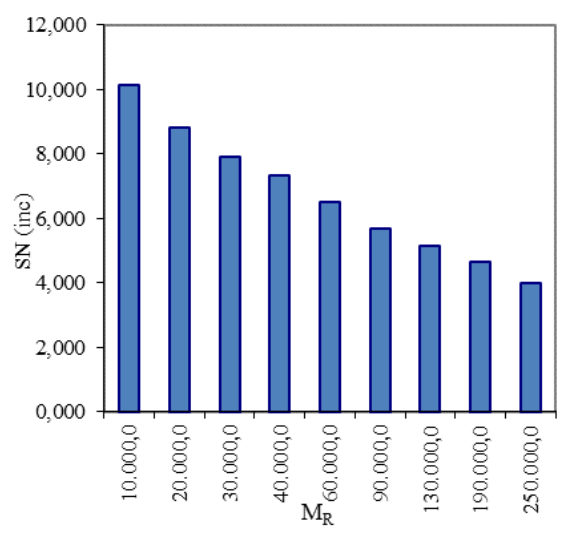

Şekil 4. SN'nin $M_{R}$ ile değişimi.

\subsubsection{AASHTO metodu ile esnek ve rijit üstyapıda taban zemini taşıma gücünün ekonomik analizi}

Yol üstyapısını oluşturan her bir tabaka kalınlığının alt ve üst limitleri bulunmaktadır. Genel olarak bir defada serilip sıkıştırılmış bitümlü karışımların tabaka kalınlığı, karışımdaki en büyük dane boyutunun 1.5 ile 3 katı arasında, temel ve alttemel tabakaları için ise bu değer $20 \mathrm{~cm}$ olmalıdır [18].

Karayolları Genel Müdürlüğü (KGM) birim fiyatlarında, aşınma, binder ve bitümlü temel tabakaları için farklı kalınlıklardaki $1 \mathrm{~m}^{2}$ maliyetleri, temel ve alttemel tabakaları için ise $\mathrm{m}^{3}$ ve ton maliyetleri verilmiştir. $\mathrm{Bu}$ çalışmada, tabaka kalınlıklarına göre verilen maliyet değerleri, tabaka kalınlıklarına bölünerek $\mathrm{m}^{2} / \mathrm{cm}$ miktarının maliyeti bulunmuş ve bu değerlerin de ortalaması alınmıştır. AASHTO (1986) metodunda taban zemini taşıma gücünün ekonomik analizi için 2018 yılı KGM birim fiyatları esas alınmıştır. Tablo 3'de analizde kullanılacak birim maliyetler verilmiştir [19]. 
$\mathrm{Bu}$ çalışmada tabaka cinslerine göre birim maliyet tespitinde, aşınma tabakası (asfalt betonu) $5 \mathrm{~cm}$, binder tabakası (asfalt betonu) $8 \mathrm{~cm}$, bitümlü temel tabakası $12 \mathrm{~cm}$, granüler temel tabakası $20 \mathrm{~cm}$ ve alttemel tabakası $20 \mathrm{~cm}$ alınmıştır.

Tablo 3. Tabaka cinslerine göre birim maliyetler.

\begin{tabular}{|c|c|c|c|c|}
\hline Poz No & Tanım & Birimi & Birim Fiyat (TL) & $\mathrm{m}^{2} / \mathbf{c m}$ Maliyeti (TL) \\
\hline KGM/6405/S & $\begin{array}{l}5 \mathrm{~cm} \text { sıkışmış kalınlıkta } 1 \mathrm{~m}^{2} \text { asfalt betonu } \\
\text { aşınma tabakası } \\
\text { (kırılmış ve elenmiş ocak taşı ile) }\end{array}$ & $\mathrm{m}^{2}$ & 9.27 & 1.85 \\
\hline KGM/6308 & 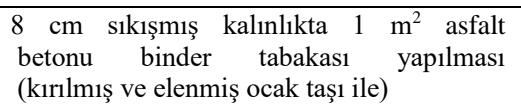 & $\mathrm{m}^{2}$ & 13.11 & 1.64 \\
\hline KGM/6212-A & $\begin{array}{l}12 \mathrm{~cm} \text { sikışmış kalınlıkta } 1 \mathrm{~m}^{2} \text { asfalt betonu } \\
\text { bitümlü sıcak temel tabakası yapılması } \\
\text { (kırılmış ve elenmiş ocak taş ile) }\end{array}$ & $\mathrm{m}^{2}$ & 18.21 & 1.52 \\
\hline KGM/6100/3 & $\begin{array}{l}\text { Plentmix temel yapılması (kırılmış ve } \\
\text { elenmiş ocak taşı ile) Not: Kaplama } \\
\text { yoğunluğu } 2.4 \mathrm{gr} / \mathrm{cm}^{3}\end{array}$ & ton & 37.63 & 0.90 \\
\hline KGM/6010 & $\begin{array}{l}\text { Elenmiş çakıllı malzeme ile alttemel } \\
\text { yapılması (kum-çakıl alttemel) }\end{array}$ & $\mathrm{m}^{3}$ & 11.32 & 0.11 \\
\hline
\end{tabular}

Tablo 3'de verilen bilgiler 1 şı̆̆ında, aşınma tabakası maliyeti $\left(\mathrm{m}^{2} / \mathrm{cm}\right)=1.85 \mathrm{TL}$, binder tabakası maliyeti $\left(\mathrm{m}^{2} / \mathrm{cm}\right)=1.64 \mathrm{TL}$, bitümlü sıcak temel tabakası maliyeti $\left(\mathrm{m}^{2} / \mathrm{cm}\right)=1.52 \mathrm{TL}$, plentmix temel tabakası maliyeti $\left(\mathrm{m}^{2}\right.$ $/ \mathrm{cm})=0,90 \mathrm{TL}$, alttemel tabakas 1 maliyeti $\left(\mathrm{m}^{2} / \mathrm{cm}\right)=0.11 \mathrm{TL}$ ve toplam maliyet $\left(\mathrm{m}^{2} / \mathrm{cm}\right)=6.02$ TL olarak bulunmuştur.

Esnek üstyapılarda $\mathrm{M}_{\mathrm{R}}$ 'nin gerçek değerinden \%50 küçük değerin alınmış olması durumunda üstyapıda \%21.34'lük fazla değer elde edilmiş olmakta ve bu durum $1 \mathrm{~m}^{2}$ üstyapı maliyetini $6.02 \times 21.34 / 100=1.284 \mathrm{TL}$ artırmaktadır. Çift şeritli bölünmüş (platform genişliği $20 \mathrm{~m}$ ) $100 \mathrm{~km}$ uzunluğundaki esnek bir üstyapıda $20 \times 100.000 \times 1.284=2.568 .000$ TL maliyet artışına sebep olmaktadır.

Tablo 4. C25 Betonun birim maliyeti

\begin{tabular}{|c|c|c|c|c|}
\hline Poz No & \multicolumn{1}{|c|}{ Tanım } & Birimi & Birim Fiyat (TL) & m²/cm Maliyeti (TL) \\
\hline Y.16.050/05 & $\begin{array}{l}\text { Beton santralinde üretilen veya satın } \\
\text { alnan ve beton pompasiyla basılan, C } \\
25 / 30 \text { basıç dayanım sinıfinda beton } \\
\text { dökülmesi (beton nakli dahil) }\end{array}$ & $\mathrm{m}^{3}$ & 165.03 & 1.65 \\
\hline
\end{tabular}

Benzer şekilde alttemel ve temel tabakası mevcut bir rijit üstyapıda, k’nın gerçek değerinden \%50 küçük değerin alınmış olması durumunda kaplama kalınlığı \%3.494 artmakta ve bu durum $1 \mathrm{~m}^{2}$ üstyapı maliyetini $1.65 \times 3.494 / 100=0.057 \mathrm{TL}$ artırmaktadır. Çift şeritli bölünmüş (platform genişliği $20 \mathrm{~m}$ ) $100 \mathrm{~km}$ uzunluğundaki rijit bir üstyapıda $20 \times 100.000 \times 0.057=114.000$ TL maliyetin artmasına sebep olmaktadır.

\section{Sonuçlar ve Tartışma}

Bu çalışmada, rijit ve esnek üstyapıların projelendirilmesinde kullanılan AASHTO (1986) metodundaki taban zemini esneklik modülü $\mathrm{M}_{\mathrm{R}}$ (psi) ile yatak katsayısı k (pci) parametrelerinin, rijit üstyapı beton kaplama kalınlığını ve esnek üstyapı sayısını ne ölçüde etkilediği araştırılmış ve zemin taşıma gücünün üstyapı maliyetine etkisi tespit edilmiştir.

Esnek üstyapılarda, esnek üstyapı sayısını en çok etkileyen parametre taban zemini esneklik modülü $M_{R}$ olmaktadır. Esnek üstyapılarda zeminin taşıma gücü $M_{R}$ 'nin gerçek değerinden \%50 küçük değerin alınmış 
olması durumunda çift şeritli bölünmüş (platform genişliği $20 \mathrm{~m}$ ) $100 \mathrm{~km}$ uzunluğundaki esnek bir üstyapıda maliyetin yaklaşı 2.568.000 TL artı̧̧ gösterdiği tespit edilmiştir. Bu nedenle esnek üstyapılarda $M_{R}$ değerinin gerçek değerinden küçük alınması durumunda yatııım giderleri gereksiz yere artırılmış ve bu durumun ekonomik zararlara yol açabileceği tespit edilmiştir.

Rijit üstyapılarda; yatak katsayısı (k) üstyapı beton kaplama kalınlığını en az etkileyen parametre olarak belirlenmiştir. Rijit üstyapıda yatak katsayısının (k)'nın gerçek değerinden \%50 küçük değerin alınmış olması durumunda çift şeritli bölünmüş (platform genişliği $20 \mathrm{~m}$ ) $100 \mathrm{~km}$ uzunluğundaki rijit bir üstyapıda maliyetin yaklaşı $114.000 \mathrm{TL}$ artış gösterdiği tespit edilmiştir. Bu nedenle rijit üstyapılarda kullanılacak beton kalitesinin artırılması ile daha az kalınlıkta beton tabaka imal edilebileceğinden ya da aynı kalınlıkta daha fazla trafik yüküne deforme olmadan direnç gösterebilecek bir kaplama oluşturulabileceğinden, tamamen yerli kaynaklarla üretilecek kaliteli betonlar ile ekonomik açıdan önemli bir kazanç sağlayacağı değerlendirilmektedir.

\section{Kaynaklar}

[1] Önal M.A, Temren, Z. Türkiye İle Bazı Avrupa Ülkelerinin Esnek Üstyapı Tasarımlarının Karşılaştırılması. 4'üncü Ulusal Asfalt Sempozyumu 2004; 224-243.

[2] Birinci F., Kalyoncuoğlu E.F., Saltan Ş, Tiğdemir M. Yol Üstyapısı Ders Notu. Samsun, 2003.

[3] Whiteoak D., Lav A. H., Lav A. 2004, Shell Bitüm El kitabı, İsfalt, İstanbul.

[4] Cilason N. Toprak Stabilizasyonu, K.G.M., Yayın No:122, Ankara. 1964.

[5] Kök B.V, Yılmaz M, Geçkil A. Çimento Stabilizasyonlu Zeminin Esnek Üstyapı Maliyetine Etkisi. Pamukkale Üniversitesi Mühendislik Bilimleri Dergisi Cilt 18, Sayı 3, 2012, Sayfa 165-172.

[6] Prabakar J, Dendorkar N, Morchhale R.K. Influence of Fly Ash on Strength Behavior of Typical Soils. Construction and Building Materials. 2004; 263-267.

[7] Senol A., Edil T.B., Bin-Shafque M.S., Acosta H.A., Benson C.H. Soft Subgrades' Stabilization by Using Various Fly Ashes. Resources, Conservation and Recycling. 2006; 365-376.

[8] Lav A.H., Lav M.A., Goktepe A.B. Analysis and Design of a Stabilized Fly Ash as Pavement Base Material Fuel. 2006; 85, 2359-2370.

[9] Chauhan M.S., Mittal S., Mohanty B. Performance Evaluation of Silty Sand Subgrade Reinforced With Fly Ash and Fibre. Geotextiles and Geomembranes. 2008 429-435

[10] Cai Y., Shi B., Charles W.W., Ng, Tang, C. Effect of Polypropylene Fibre and Lime Admixture on Engineering Properties of Clayey. Soil Engineering Geology. 2006; 230-240.

[11] Gerald A., Miller U., Azadb S. Influence of Soil Type on Stabilization With Cement Kiln Dust. Construction and Building Materials. 2000; 89-97

[12] Dermatas D., Meng X. Utilization of Fly Ash For Stabilization/Solidifcation of Heavy Metal Contaminated Soils. Engineering Geology. 2003; 377-394.

[13] Eren S., Filiz M. Comparing the Conventional Soil Stabilization Methods To The Consolid System Used as an Alternative Admixture Matter in Isparta Darıdere Material. Construction and Building Materials. 2009; 2473-2480.

[14] Wu Z., Zhang Z., Tao M. Stabilizing Blended Calcium Sulfate Materials For Roadway Base Construction. Construction and Building Materials. 2010; 1861-1868.

[15] Porter O. James. Development of the Original Method for Highway Design. Transactions, American Society of Civil Engineers, 1950; 461-67.

[16] American Association of State Highway and Transportation Officials, AASHTO Guide for Design of Pavement Structures. Washington, D.C.: 1993.

[17] Ağar E., Sütaş İ., Öztaş G. Beton Yollar. İstanbul. İTÜ Yayınları,1998.

[18] Karayolları Genel Müdürlüğü, Yollar Fenni Şartnamesi. 170/2, 1989.

[19] http://www.birimfiyat.net, 2018. 